\title{
Challenges in diagnosing extrapulmonary tuberculosis in the European Union, 2011
}

I Solovic ${ }^{1}$, J Jonsson 2 , M Korzeniewska- Koseta 3 , D I Chiotan4, A Pace-Asciak5, E Slump ${ }^{6}$, R Rumetshofer7, I Abubakar ${ }^{8}$, K Kos $^{9}$,

P Svetina-Sorli ${ }^{10}$, W Haas $^{11}$, T Bauer ${ }^{12}$, A Sandgren ${ }^{13}$, M J van der Werf (Marieke.vanderwerf@ecdc.europa.eu) ${ }^{13}$

1. Catholic University, Ružomberok, Slovakia

2. Swedish Institute for Infectious Disease Control, Stockholm, Sweden

3. National Tuberculosis and Lung Diseases Research Institute, Warsaw, Poland

4. Romanian National Tuberculosis Programme, Institute of Pneumology Marius Nasta, Bucharest Romania

5. Infectious Disease Prevention and Control Unit, Health Promotion and Disease Prevention Directorate, Superintendence of Public Health, Ministry of Health, the Elderly and Community Care, Malta

6. RIVM-Centre Infectious Disease Control, The Netherlands

7. Tuberkulosestation Karlshaus, Otto Wagner Spital, Vienna, Austria

8. Research Department of Infection and Population Health, University College London, United Kingdom

9. Lung Hospital Janov, Mirosov, Czech Republic

10. University Clinic Golnik, Register for TB, Slovenia

11. Robert Koch Institute, Berlin, Germany

12. German Committee against Tuberculosis (DZK), Berlin Germany

13. European Centre for Disease Prevention and Control, Stockholm, Sweden

Citation style for this article:

Solovic I, Jonsson J, Korzeniewska- Koseła M, Chiotan DI, Pace-Asciak A, Slump E, Rumetshofer R, Abubakar I, Kos S, Svetina-Sorli P, Haas W, Bauer T, Sandgren A, van der Werf MJ. Challenges in diagnosing extrapulmonary tuberculosis in the European Union, 2011. Euro Surveill. 2013;18(12):pii=20432. Available online: http://

www.eurosurveillance.org/ViewArticle.aspx?Articleld $=20432$

Article submitted on 08 November 2012/ published on 21 March 2013

In the European Union (EU) 72,334 tuberculosis (TB) cases were notified in 2011 , of which 16,116 (22\%) had extrapulmonary tuberculosis (EPTB). The percentage of TB cases with EPTB ranged from $4 \%$ to $48 \%$ in the reporting countries. This difference might be explained by differences in risk factors for EPTB or challenges in diagnosis. To assess the practices in diagnosis of EPTB we asked European Union/European Economic Area (EU/EEA) countries to participate in a report describing the diagnostic procedures and challenges in diagnosing EPTB. Eleven EU Member States participated and reports showed that in the majority EPTB is diagnosed by a pulmonologist, sometimes in collaboration with the doctor who is specialised in the organ where the symptoms presented. In most countries a medical history and examination is followed by invasive procedures, puncture or biopsy, to collect material for confirmation of the disease (by culture/histology/ cytology). Some countries also use the tuberculin skin test or an interferon-gamma-release-assay. A wide variety of radiological tests may be used. Countries that reported challenges in the diagnosis of EPTB reported that EPTB is often not considered because it is a rare disease and most medical professionals will not have experience in diagnosing EPTB. The fact that EPTB can present with a variety of symptoms that may mimic symptoms of other pathologies does pose a further challenge in diagnosis. In addition, obtaining an appropriate sample for confirmation of EPTB was frequently mentioned as a challenge. In summary, diagnosis of EPTB poses challenges due to the diversity of symptoms with which EPTB may present, the low level of suspicion of clinicians, and due to the difficulty in obtaining an adequate sample for confirmation.

\section{Introduction}

Tuberculosis (TB) is an airborne infectious disease caused by Mycobacterium tuberculosis. It most commonly affects the lungs, but it can affect virtually any organ. A case with TB in any site other than pulmonary is considered an extrapulmonary TB (EPTB) case. In 2011, globally 6.2 million TB cases were notified and 0.8 million cases with EPTB [1]. The most common site of EPTB is lymph nodes [2]. Other sites include pleura, urogenital tract, bones and joints, meninges, central nervous system (CNS), bowel and/or peritoneum, pericardium, and skin. Some types of EPTB, e.g. tuberculosis meningitis, cause substantial mortality and morbidity in children and adults [3].

Studies from the Netherlands and United States showed that EPTB is more often diagnosed in women and is associated with ethnic minorities and those born in other countries $[2,4-6]$. Also, studies from different geographical areas have shown that human immunodeficiency virus (HIV)-infected individuals have a higher frequency of EPTB [2,5-7]. In general, EPTB affects people with a weak immune system caused by diabetes, HIV, or malnourishment, very young children and elderly, or those undergoing prolonged treatment with chemotherapy or cortisone [5].

Since EPTB can affect virtually all organs, it has a wide variety of clinical manifestations, which may cause difficulty and delay in diagnosis. This is illustrated by the many published case reports $[8,9]$. It is also illustrated 
by the longer health system delays in diagnosis of EPTB compared to pulmonary TB [10-12].

In the European Union (EU) 16,116 EPTB cases were notified in 2011 , i.e. $22 \%$ of all TB cases [13]. The percentage of TB cases with EPTB differed widely from $4 \%$ of all notified TB cases in Hungary up to $48 \%$ in the United Kingdom (UK). This difference might be explained by differences in risk factors for EPTB. However, it could also result from challenges in diagnosis. In this study we assessed the challenges in diagnosing EPTB in EU/ European Economic Area (EEA) countries.

\section{Methods}

We approached the officially nominated EU/EEA national TB surveillance contacts points for the European Centre for Prevention and Control (ECDC) in Stockholm, Sweden, by email in August 2012 and asked whether they were interested in participating in a study on diagnosing EPTB. Those who indicated interest were requested to provide a description of practices leading to EPTB diagnosis in their country. They were specifically asked to answer the following questions: (i) what are the procedures for diagnosing EPTB in your country?; (ii) who is in charge of diagnosing and treating EPTB in your country?; and (iii) what are specific challenges in the diagnosis of EPTB in your country? In addition, we asked whether the country had guidelines available for diagnosis of EPTB.

Contact points were asked to submit a report by 1 October 2012. The reports were reviewed and edited and the edited versions were shared between the participating countries, which were particularly asked to answer follow-up questions and provide corrections and additional clarifications to their own report.

In addition to the country reports we retrieved data on pulmonary and EPTB from the 'Tuberculosis surveillance and monitoring in Europe, 2013 (situation in 2011) report', for the 11 countries that participated in the study [14].

\section{Country reports}

The countries that participated in the study consisted of $11 \mathrm{EU}$ Member States. In Table 1 and 2, we provide the main epidemiological information about pulmonary and EPTB in the 11 countries. All countries provided a description of the procedures to diagnose EPTB. Nine Member States additionally referred to guidelines available in their country for EPTB diagnosis (Table 3). Below we provide the country descriptions in alphabetical order. For all countries, the initial diagnosis relied on a medical examination, but in this study more

TABLE 1

Tuberculosis and extrapulmonary tuberculosis notification numbers, rates, and percentages in 11 European Union Member States, 2011

\begin{tabular}{|c|c|c|c|c|c|}
\hline \multirow{2}{*}{ Country } & \multicolumn{2}{|c|}{ All TB cases } & \multicolumn{2}{|c|}{$\begin{array}{l}\text { TB cases with } \\
\text { extrapulmonary TB }\end{array}$} & \multirow{2}{*}{ Extrapulmonary TB \% } \\
\hline & $\mathrm{N}$ & $\begin{array}{l}\text { Notification rate per } \\
100,000 \text { population }\end{array}$ & N & $\begin{array}{l}\text { Notification rate per } \\
100,000 \text { population }\end{array}$ & \\
\hline Austria $^{a}$ & 687 & 8.2 & 136 & 1.6 & 20 \\
\hline Czech Republic & 600 & $5 \cdot 7$ & 78 & 0.7 & 13 \\
\hline Germany $^{\mathrm{a}}$ & 4,316 & 5.3 & 926 & 1.1 & 21 \\
\hline Malta & 33 & 7.9 & 11 & 2.6 & 33 \\
\hline Netherlands & 1,007 & 6.0 & 441 & 2.6 & 44 \\
\hline Poland & 8,478 & 22.2 & 599 & 1.6 & 7 \\
\hline Romania & 19,212 & 89.7 & 2,781 & 13.0 & 14 \\
\hline Slovakia & 399 & 7.3 & 62 & 1.1 & 16 \\
\hline Slovenia & 192 & 9.4 & 27 & 1.3 & 14 \\
\hline Sweden & 586 & 6.2 & 228 & 2.4 & 39 \\
\hline United Kingdom ${ }^{a}$ & 8,963 & $14 \cdot 3$ & 4,313 & 6.9 & 48 \\
\hline
\end{tabular}

TB: tuberculosis.

It was not reported whether TB was pulmonary or extrapulmonary for 11 TB cases in Austria, 44 TB cases in Germany and 47 TB cases in the United Kingdom.

Source: [14]. 
TABLE 2

Major sites of extrapulmonary tuberculosis in 11 European Union Member States, 2011

\begin{tabular}{|c|c|c|c|c|c|c|c|c|c|c|}
\hline \multirow[b]{2}{*}{ Country } & \multicolumn{10}{|c|}{ Site of extrapulmonary tuberculosis } \\
\hline & $\begin{array}{l}\text { Lymphatic } \\
\text { N (\%) }\end{array}$ & $\begin{array}{l}\text { Pleural } \\
\text { N (\%) }\end{array}$ & $\begin{array}{l}\text { Urogenital } \\
\text { N (\%) }\end{array}$ & $\begin{array}{l}\text { Bone } \\
\text { N (\%) }\end{array}$ & $\begin{array}{l}\text { Spinal } \\
\text { N (\%) }\end{array}$ & $\begin{array}{l}\text { Gastro- } \\
\text { intestinal } \\
\mathrm{N}(\%)\end{array}$ & $\begin{array}{l}\text { Meningal } \\
\mathrm{N}(\%)\end{array}$ & $\begin{array}{c}\text { Disseminated } \\
N(\%)\end{array}$ & $\begin{array}{l}\text { CNS } \\
\text { other } \\
\mathrm{N}(\%)\end{array}$ & $\begin{array}{c}\text { Other extra- } \\
\text { pulmonary } \\
\mathrm{N}(\%)\end{array}$ \\
\hline Austria & $65(48)$ & $20(15)$ & $16(12)$ & $8(6)$ & $3(2)$ & $8(6)$ & $1(1)$ & $2(1)$ & $2(1)$ & $11(8)$ \\
\hline Czech Republic & $34(44)$ & $16(21)$ & $6(8)$ & $2(3)$ & $6(8)$ & $\mathrm{o}(\mathrm{o})$ & $\mathrm{o}(\mathrm{o})$ & $\mathrm{o}(\mathrm{o})$ & $2(3)$ & $12(15)$ \\
\hline Germany & $431(47)$ & $147(16)$ & $90(10)$ & $67(7)$ & $34(4)$ & $43(5)$ & $22(2)$ & $13(1)$ & $9(1)$ & $70(8)$ \\
\hline Malta & $6(55)$ & $1(9)$ & $1(9)$ & $\mathrm{o}(0)$ & $1(9)$ & $\mathrm{o}(0)$ & $1(9)$ & $\mathrm{o}(\mathrm{o})$ & $\mathrm{o}(0)$ & $1(9)$ \\
\hline Netherlands & $225(51)$ & $64(15)$ & $19(4)$ & $11(2)$ & $26(6)$ & $33(7)$ & $3(1)$ & o (o) & $7(2)$ & $53(12)$ \\
\hline Poland & $149(25)$ & $214(36)$ & $68(11)$ & $40(7)$ & $35(6)$ & $12(2)$ & $10(2)$ & $16(3)$ & $2(0)$ & $53(9)$ \\
\hline Romania & 535 (19) & $1,606(58)$ & $117(4)$ & $89(3)$ & $129(5)$ & $65(2)$ & $129(5)$ & $\mathrm{o}(\mathrm{o})$ & $3(0)$ & $108(4)$ \\
\hline Slovakia & $20(32)$ & $18(29)$ & $7(11)$ & $\mathrm{o}(0)$ & $13(21)$ & $1(2)$ & $\mathrm{o}(0)$ & $\mathrm{o}(0)$ & $\mathrm{o}(\mathrm{o})$ & $3(5)$ \\
\hline Slovenia & $10(37)$ & $11(41)$ & $1(4)$ & $1(4)$ & $1(4)$ & $3(11)$ & $\mathrm{o}(0)$ & $\mathrm{o}(0)$ & $\mathrm{o}(0)$ & $\mathrm{o}(0)$ \\
\hline Sweden & $139(61)$ & $15(7)$ & $2(1)$ & $11(5)$ & $19(8)$ & $20(9)$ & $5(2)$ & o (o) & $3(1)$ & $14(6)$ \\
\hline United Kingdoma & $2,360(49)$ & $492(10)$ & $130(3)$ & $181(4)$ & $320(7)$ & $349(7)$ & $150(3)$ & $89(2)$ & $61(1)$ & $647(14)$ \\
\hline
\end{tabular}

CNS: central nervous system.

a United Kingdom data were provided by the Health Protection Agency and data were provided for all sites of extrapulmonary tuberculosis for a case. The 4,313 extrapulmonary tuberculosis cases had 4,779 sites of disease.

Source: [14].

TABLE 3

Availability of guidelines for the diagnosis of extrapulmonary tuberculosis in 11 European Union Member States, 2012

\begin{tabular}{|c|c|c|c|}
\hline Country & $\begin{array}{l}\text { Guidelines for diagnosis of } \\
\text { extrapulmonary TB available (yes/no) }\end{array}$ & If guidelines available, name of document & References \\
\hline Austria & No & NA & NA \\
\hline Czech Republic & Yes & $\begin{array}{l}\text { TBC dospělých. Standard léčebného plánu; Standard léčebného } \\
\text { plánu - tuberkulóza dětí a mladistvých }\end{array}$ & {$[23,24]$} \\
\hline Germany & Yes $^{\mathrm{a}}$ & $\begin{array}{c}\text { Empfehlungen zur Therapie, Chemoprävention und } \\
\text { Chemoprophylaxe der Tuberkulose im Erwachsenen- und } \\
\text { Kindesalter }\end{array}$ & [25] \\
\hline Malta & Yes & $\begin{array}{c}\text { Prevention, Control and Management of Tuberculosis - A } \\
\text { National Strategy for Malta }\end{array}$ & [26] \\
\hline Netherlands & Yes $^{\mathrm{b}}$ & $\begin{array}{c}\text { Handboek TBC-bestrijding Nederland; } \\
\text { NVMM-richtlijn Mycobacteriële laboratoriumdiagnostiek }\end{array}$ & {$[21,27]$} \\
\hline Poland & Yes & Podręcznik gruźlicy-zalecenia NPZG & [17] \\
\hline Slovakia & Yes & $\begin{array}{l}\text { Professional guidance of the Ministry of Health for the } \\
\text { management of tuberculosis and other mycobacteriosis and for } \\
\text { screening and follow up in the field of phthisiology }\end{array}$ & [28] \\
\hline Slovenia & Yes & $\begin{array}{c}\text { National Tuberculosis Programme Slovenia - Clinical diagnosis } \\
\text { and treatment of TB }\end{array}$ & [29] \\
\hline Sweden & Yes & Tuberkulos - Vägledning för sjukvårdspersonal & [30] \\
\hline Romania & $\mathrm{No}^{\mathrm{c}}$ & NA & NA \\
\hline United Kingdom & Yes & $\begin{array}{l}\text { Tuberculosis: clinical diagnosis and management of } \\
\text { tuberculosis, and measures for its prevention and control }\end{array}$ & {$[20]$} \\
\hline
\end{tabular}

NA: not applicable; TB: tuberculosis.

a Guidelines for diagnosis of extrapulmonary TB are partially available.

b The guidelines for diagnosis of extrapulmonary TB are focused on laboratory diagnostics.

c Although some recommendations are included in the norms for the implementation of the Romanian TB programme. 
emphasis is given to the tests to confirm the clinical diagnosis.

\section{Austria}

Between 2008 and 2011, 120 to 140 cases of EPTB were diagnosed, which accounted for $16 \%$ to $20 \%$ of all TB patients. The TB incidence was about 8/100,000 population. The most common forms of EPTB were lymphatic TB (65 cases, $48 \%$ of all EPTB), pleural TB (20 cases, $15 \%$ of all EPTB), and urogenital TB (16 cases, $12 \%$ of all EPTB) (Table 2).

The majority of the EPTB patients are diagnosed at pulmonary in-patient clinics. When patients are diagnosed outside of pulmonary clinics, e.g. internal medicine wards, infection control and hygienic representatives are usually involved. Patients diagnosed outside pulmonary clinics are normally referred to a pulmonary clinic for initiation of TB treatment. The continuationphase of the treatment is under observation and is organised between out-patient pulmonary physicians and public health services. In paediatric cases, treatment is initiated and managed in paediatric units.

One of the main challenges is the fact that EPTB is often not considered as a potential differential diagnosis. Due to the fact that there is no suspicion of TB, diagnostic specimens, such as biopsies or surgical specimens, are fixed and immersed in formalin or other preserving agents and are therefore not suitable for microbiological culture testing. Those specimens can still be used for polymerase chain reaction (PCR) analysis.

In Austria, anecdotal evidence suggests that TB treatment is often initiated late in EPTB patients. Collection of data on the duration of diagnostic delay and correct diagnosis of TB might be useful to confirm this and if the case to sensitise physicians.

\section{Czech Republic}

In 2011, there were 600 cases of TB reported to the TB register of the Czech Republic (notification rate $5.7 / 100,000$ population) of which 78 (13\%) cases were diagnosed with EPTB (Table 1).

The procedures used in the Czech Republic to diagnose EPTB are radiology, microbiology, histology and clinical evaluation. Of the 78 cases with EPTB, 31 (40\%) were bacteriologically confirmed.

The most common forms of EPTB were lymphatic TB (34 cases, $44 \%$ of all EPTB cases), pleural TB (16 cases, $21 \%$ of all EPTB cases), spinal TB (6 cases, $8 \%$ of all EPTB cases), and urogenital TB (6 cases, $8 \%$ of all EPTB cases) (Table 2 ).

Diagnosis of EPTB is normally performed by pulmonologists/phthisiologists in cooperation with the relevant specialist. EPTB is a rare diagnosis and therefore it is often not taken into consideration. Treatment is conducted by pulmonologists/phthisiologists.

\section{Germany}

In 2011, 926 EPTB cases accounted for $21 \%$ of all notified TB cases in Germany (Table 1). The proportion of EPTB has remained stable since 2001, when EPTB accounted for $20 \%$ of all TB. The most common forms of EPTB were lymphatic TB (431 cases, $47 \%$ of all EPTB cases), pleural TB (147 cases, $16 \%$ of all EPTB cases) and urogenital TB (90 cases, $10 \%$ of all EPTB cases) (Table 2). The majority of EPTB patients in Germany were foreign born ( $57 \%$ in 2011).

The most common procedure for diagnosing extrathoracic lymph nodes is direct puncture of the node or extirpation. Intrathoracic lymph nodes are punctured by endobronchial ultrasound or surgically by mediastinoscopy. For pleural disease, surgical or medical thoracoscopy and/or needle biopsy are the most common procedures. All procedures include direct microscopy and culture of the pleural fluid. Urogenital TB is diagnosed either in urine or the affected organ itself. Direct staining of the liquor and culture of the liquor are the most common confirmative diagnostic methods for CNS TB, but computed tomography (CT) and magnetic resonance imaging (MRI) together with the clinical evaluation remain tools for diagnosis.

Culture confirmation was positive in $59 \%$ of reported EPTB cases, the lowest culture confirmation rate was for CNS TB.

EPTB, especially TB of the lymph nodes, is treated by pulmonary or infectious diseases specialists. CNS and urogenital TB is usually also treated by neurologists and urologists.

\section{Malta}

Between 2001 and 2011, a total of 94 cases of EPTB were reported and the notification rates increased from $0.26 / 100,000$ to $2.6 / 100,000$ (P<0.001). The proportion of EPTB increased from $6 \%(1 / 16)$ to $33 \%(11 / 33)$ $(P=0.04)$. In 2011 , the most common forms of EPTB were lymphatic TB (6 cases, $54 \%$ of all EPTB cases) (Table 2). Sixty-two percent (58/94) of EPTB cases over the whole 2001 to 2011 period were among undocumented African migrants. The notification rate of EPTB in undocumented African migrants was 106/100,000 compared to $0.54 / 100,000$ in people born in Malta (chisquared test, $\mathrm{P}=0.001$ ).

Diagnosis includes a medical history and examination, a tuberculin skin test (TST) and an interferongamma-release-assay (IGRA) test. A chest X-ray is also done to exclude or confirm co-existing pulmonary TB. Other radiological tests may be indicated. Appropriate specimens are sent for histology and microbiology. Microbiological specimens are tested for acid-fast bacilli (AFB) and then cultured for Mycobacterium tuberculosis complex, including those that are AFB negative. 
According to national TB guidelines, all patients suspected of EPTB are referred to infectious disease/TB specialists at the main hospital who are responsible for the diagnosis and treatment. However, since EPTB may occur in any organ, diagnosis may be initiated by the relevant specialist of the affected site. Between 2006 and 2011, 84\% (61/73) of the EPTB cases had specimens sent for culture. Treatment is started without waiting for culture results if the test for acid-fast bacilli (direct Ziehl-Neelsen test) and the clinical picture are consistent with a diagnosis of TB. Treatment is continued even if subsequent culture results are negative.

A particular challenge regarding EPTB in Malta is detection of these cases in undocumented African migrants. EPTB (except thoracic EPTB) is detected by passive surveillance. National studies have noted that passive surveillance may not be very effective in detecting TB cases in migrants [15]. Even though migrants have free access to TB healthcare in Malta, they may have difficulties in approaching the healthcare system due to lack of information, language or cultural barriers [16]. This may cause diagnostic delays.

\section{Netherlands}

In 2011, 441 (44\%) of the 1,007 notified TB cases in the Netherlands were diagnosed with EPTB (Table 1). The most common forms of EPTB were lymphatic TB (225 cases, $51 \%$ of all EPTB cases), pleural TB (64 cases, $51 \%$ of all EPTB cases) and urogenital TB (19 cases, $4 \%$ of all EPTB cases) (Table 2). The majority of TB patients in the Netherlands were foreign born ( 710 foreign born cases, 71 of all cases) and the percentage of EPTB cases was highest in this group.

EPTB is diagnosed based on clinical symptoms, a matching medical history, risk factors indicating likelihood of infection with $M$. tuberculosis, such as exposure to an infectious TB patient and origin from or travel to an high endemic area, as well as results of histological or bacteriological tests of body material. TST and IGRA are not recommended for the diagnosis of EPTB. However, in some cases they may provide supportive evidence.

The majority of patients with symptomatic EPTB were diagnosed by lung physicians (194 cases, $44 \%$ of all EPTB cases) and other clinical specialists (185 cases, $42 \%$ of all EPTB cases). In most cases, when TB is suspected or diagnosed in a clinical setting, a lung physician takes charge of further diagnosis and treatment. Ten to $15 \%$ of the patients with EPTB were diagnosed by Municipal Health Services through screening of risk groups and contact investigation.

Since the absolute number of patients diagnosed with EPTB is low, most medical professionals will only rarely be involved in diagnosis and treatment of EPTB. It is therefore a challenge to maintain sufficient knowledge among clinicians to avoid diagnostic delays.
Another challenge is the confirmation of the diagnosis of EPTB because it can be difficult to obtain a sample and to confirm the diagnosis with a positive culture. In the group detected through active case finding in 2011, $17 \%(8 / 47)$ of the cases were confirmed by culture and $2.1 \%(1 / 47)$ through PCR or histology. Over the years in the period from 2005 to $2011,64 \%(1,698 / 2,659)$ of the EPTB cases found through passive case finding were confirmed by culture and an additional $10 \%(262 / 2,659)$ were confirmed by PCR or histology.

\section{Poland}

In 2011, 599 EPTB cases without coexisting pulmonary TB were notified, $7 \%$ of all TB cases (notification rate 1.6/100.000) (Table 1). For several years the percentage of EPTB has been low. The reason may be insufficient awareness, difficulties in diagnosis or low prevalence of factors which are considered risk factors for EPTB. The most common forms of EPTB were pleural TB (214 cases, 36\% of all EPTB cases), lymphatic TB (149 cases, $25 \%$ of all EPTB cases), and urogenital TB (68 cases, $11 \%$ of all EPTB cases).

Guidelines for the diagnosis of EPTB in Poland are included in the TB manual that was issued in 2001 (Table 3) [17]. Diagnosis is done either by pulmonologists or by others specialists, depending on the site of EPTB. The most common situation is that doctors are supported by pulmonologists in the diagnosis of EPTB. Pulmonologists are responsible for the treatment of EPTB cases. If hospitalisation is required, patients are usually treated in TB wards, under the responsibility of pulmonologists. Cases of TB/HIV co-infection are most often diagnosed by infectious diseases specialists and often also treatment is provided by infectious diseases specialists.

The doctor performing the diagnosis decides whether and which invasive procedures are used for obtaining clinical material for microbiological diagnosis. Pulmonologists believe that TB is too often diagnosed without microbiological confirmation (only $35 \%$ of the EPTB cases were bacteriologically confirmed between 2007 and 2011) and for this reason there may be substantial over-diagnosis. For example, pleural TB was bacteriologically confirmed in $56 \%$ of the cases in 2011; pericardial TB was confirmed in $50 \%$ of the reported cases; and intrathoracic lymphatic TB in children was confirmed in only $13 \%$ of the cases.

In Poland, data on delay in diagnosis of EPTB are not collected. However, pulmonologists consider based on anecdotal evidence that other specialists are not aware of TB.

\section{Romania}

In 2011, 2,781 EPTB cases were notified, accounting for $14 \%$ of all TB cases (Table 1). The proportion of EPTB increased from $11 \%$ in 2002 to $14 \%$ in 2011 . The most common forms of EPTB were pleural TB $(1,606$ cases, 
$58 \%$ of all EPTB cases), lymphatic TB (535 cases, $19 \%$ of all EPTB cases), and spinal TB and TB meningitis (both 129 cases, $5 \%$ of all EPTB cases). Between 8\% and $10 \%$ of the EPTB cases were bacteriologically confirmed by smear and culture according to the national electronic TB data base.

Diagnosis of EPTB is done by organ specific specialists together with the pulmonologist, while treatment of EPTB cases is managed by pulmonologists.

Often patients with EPTB will need several diagnostic procedures by different medical units to establish the diagnosis. For example, lymph node TB will be investigated by the pulmonologist, who will also assess epidemiological links with known TB patients, and might perform a TST and/or IGRA, chest X-ray, bronchoscopy, smear and culture, and histopathological examination of the specimen obtained by puncture or biopsy. Furthermore, ultrasound imaging might be performed at the Excellence Centre for Endoscopy. A radiologist might be involved to evaluate the lymph node using CT or MRI. Finally a surgeon might do a biopsy or remove the lymph node.

The involvement of different persons in the diagnosis may cause diagnostic delays.

\section{Slovakia}

In Slovakia, 399 TB cases were notified in 2011 (7.3/100,000 population). Of those 62 (16\%) were diagnosed with EPTB. The most common forms of EPTB were lymphatic TB (20 cases, $32 \%$ of all EPTB cases), pleural TB (18 cases, $29 \%$ of all EPTB cases), and spinal TB ( 13 cases, $21 \%$ of all EPTB cases).

The standard procedure for diagnosing EPTB is puncture or biopsy for culture and histology or/and cytology. Eighteen percent of the EPTB cases were bacteriologically confirmed. Histological and cytological confirmation was obtained in $28 \%$.EPTB is also diagnosed based on clinical symptoms, medical history, risk factors, such as close contact with TB patients, presence of TB in the family, patients who have immigrated from high incidence settings, and results of histological or bacteriological tests of body material. TST and IGRA tests are also used. Diagnostic tests are performed after a specialist refers the suspected EPTB case to the National Institute for TB, Lung Diseases and Thoracic Surgery for further investigation. In 2011, in $33(54 \%)$ EPTB cases the decision of the clinician to start TB treatment was based on clinical symptoms, history and non-specific examinations' results.

Thirty-seven (60\%) patients with symptomatic EPTB were diagnosed by pulmonologists and other clinical specialists. In most cases, when TB is suspected or diagnosed, a lung physician is involved and is responsible for further diagnosis and treatment. If hospitalisation is required, usually patients are treated in the specialised EPTB wards of the National TB Institute, under the care of a pulmonologist in collaboration with other specialists.

The main challenge is to maintain sufficient knowledge on TB among clinicians to avoid long diagnostic delays in those with symptomatic EPTB. EPTB is too often diagnosed empirically without microbiological confirmation and for this reason often over-diagnosed.

\section{Slovenia}

In 2011, 192 cases of TB were notified in Slovenia, 133 (69\%) with pulmonary TB, 27 (14\%) with EPTB and 32 patients (17\%) with pulmonary TB and EPTB. The most common forms of EPTB were pleural TB (11 cases, $41 \%$ of all EPTB cases) lymphatic TB (10 cases, $37 \%$ of all EPTB cases) and gastrointestinal TB (3 cases, $11 \%$ of all EPTB cases). In 23 ( $85 \%$ of all EPTB cases) cases, diagnosis was based on typical histological images, and confirmed by culture from biopsy material. In four $(15 \%$ of all EPTB cases) patients, the disease was not culture confirmed. EPTB was diagnosed post mortem based on histology in three patients. In the past five years the proportion of patients with EPTB varied between 14 and $18 \%$.

According to the recommendations of the National TB programme and the guidelines for diagnosis and treatment of TB, all patients suspected of EPTB should be confirmed by culture before starting treatment. Often pulmonologist cooperate with specialists from other specialties, such as orthopaedic surgeons, thoracic surgeons, urologists and others to diagnose EPTB.

Pulmonologists are responsible for the treatment of both pulmonary TB and EPTB. Pulmonary TB should be excluded using relevant samples in patients suspected or diagnosed with EPTB.

\section{Sweden}

In 2011, 586 TB cases were notified in Sweden of which 228 (39\%) had EPTB. During the last five years (2007 to 2011) the percentage of EPTB of all TB cases reported has been quite stable with an average of $40 \%$. The high percentage of EPTB might be due to good coverage of reporting. The most common forms of EPTB were lymphatic TB (139 cases, $61 \%$ of all EPTB cases), gastrointestinal TB (20 cases, $9 \%$ of all EPTB cases), and spinal TB (19 cases, $8 \%$ of all EPTB cases).

The standard procedure for diagnosing EPTB is puncture or biopsy for culture and histology/cytology. Puncture and/or biopsy are most frequently performed to diagnose lymph node TB. However, it is also performed if TB is suspected at other sites, including skeletal and gastrointestinal TB. To diagnose TB in intrathoracical lymph nodes, endobronchial puncture or biopsy through mediastinoscopy is considered. TB of the CNS (meningitis, tuberculoma) is also confirmed by culture. The only type of EPTB that is never confirmed by culture is retinal TB. The diagnosis is always on suspicion of an ophthalmologist who refers to a clinic of infectious 
diseases for further investigation; i.e. chest X-ray and immunological tests like IGRA. Often an ex-juvantibus treatment will be initiated and the ophthalmologist will follow the clinical course. Of the EPTB cases an average of $70 \%$ is bacteriologically confirmed. An additional five to $10 \%$ is diagnosed by histology showing necrotising granuloma and the remaining on clinical grounds.

Infectious disease clinics are in charge of diagnosing and treating all cases of EPTB (and in most regions also pulmonary TB), but diagnosis might happen in another speciality, depending on the presenting symptoms. Paediatricians usually care for EPTB cases in children <18 years of age, often in co-operation with the infectious disease clinic.

\section{United Kingdom}

In the UK the proportion of cases with TB in extra pulmonary sites has steadily increased over the last decade [18]. In 2011, 48\% (4,313 EPTB cases/8,963 TB cases) of EPTB cases were diagnosed with exclusive EPTB with a further 828 cases having disease affecting both pulmonary and extrapulmonary sites. In the UK all sites of EPTB are registered. In total 4,779 different sites were registered for the 4,313 EPTB cases. The most common forms of EPTB were lymphatic TB, 2,390/4,779 (49\%), pleural TB, 492/4,779 (10\%), and gastrointestinal TB, 349/4,779 (7\%).

The diagnosis of patients often requires specific procedures to obtain samples such as lumbar puncture and a brain scan (MRI or CT) in those with CNS TB. The UK National Institute for Health and Clinical Excellence has outlined recommendations for the diagnosis of EPTB $[19,20]$.

As EPTB can affect several organs, its clinical presentation may mimic symptoms and signs of other pathologies. Inevitably, patients present to the clinical speciality that usually treats the commonest differential diagnoses for each site of disease. For example, renal TB may be diagnosed by nephrologists, CNS TB may present to neurologists and skin TB to dermatologists. In general, patients with EPTB are managed with support from experts with knowledge of TB.

\section{Discussion}

In 2011, 72,334 TB cases were notified by 29 EU/EEA countries. Of these 16,116 (22\%) were EPTB cases [13]. In the EU/EEA countries, extrapulmonary TB was more frequent in females, in children, and in individuals who were foreign born or had citizenship from another country [13]. The percentage of TB cases with EPTB notified by the different EU/EEA countries ranged from 4 to $48 \%$ (and $67 \%$ in Iceland with 6 EPTB cases). In the countries presented in this study the percentage EPTB ranged from $7 \%$ in Poland to $48 \%$ in the UK.

Several countries have recommendations for the diagnosis of EPTB (Table 3). The UK recommendations specify what imaging technique should be used for each site, what type of biopsy should be performed and which material should be cultured [20]. The guidelines in the Netherlands are focused on laboratory diagnostics [21]. In most other countries a medical history and examination is followed by invasive procedures, puncture or biopsy, to collect material for confirmation (culture/histology/cytology/PCR) of the disease. Some countries (Malta, Slovakia and Romania) also use TST or IGRA. A wide variety of imaging tests may be used: ultrasound, CT or MRI.

Not all countries reported challenges in the diagnosis of EPTB, but those that did, reported that EPTB is often not considered because it is a rare disease and therefore not included in the differential diagnosis. If TB is not considered body material will not be sent for bacteriological confirmation or will be processed in such a way that it will not be subsequently usable for bacteriological confirmation if EPTB is suspected at a later stage. In cases where TB is considered, it is often difficult to obtain body material to confirm the diagnosis. Diagnosis of EPTB might require several diagnostic procedures by different medical units. The involvement in the diagnosis of different persons/units may cause a delay in diagnosis. The fact that EPTB can present with a variety of symptoms that may mimic symptoms of other pathologies poses a further challenges in diagnosis.

Since by definition EPTB does not affect the lung parenchyma, the tracheobronchial tree, EPTB patients will normally not present to pulmonologists. They will seek care from a general practitioner, a paediatrician or from an organ specific specialist who will infrequently encounter an EPTB case and do therefore not include EPTB in their differential diagnosis. The countries reported that in the majority of cases, EPTB is diagnosed by a pulmonologist, sometimes in collaboration with the organ specific specialist. Alternatively, e.g. in Malta, patients suspected of EPTB are referred to infectious disease or TB specialists. Thus, patients with EPTB need be referred from a more generalist doctor, or organ specific specialist, to a pulmonologist. This may increase the diagnostic delay.

Longer health system delays in diagnosis of EPTB compared to pulmonary TB have been reported [10-12]. The countries participating in this study did not have data available on delays in diagnosis, but anecdotal evidence suggests that delays in diagnosis of EPTB might be long. Systematic collection of information on diagnostic delay might be useful to understand the extent of the problem and to sensitise physicians.

In most countries, the treatment of EPTB is the responsibility of the pulmonologist. In some countries, such as Sweden and the UK, infectious disease specialists are involved or responsible for treatment of EPTB cases. Paediatricians are involved in the treatment of EPTB in children. Since TB and EPTB is a rare disease in most EU/EEA countries not all clinicians have 
experience with the treatment. To guarantee adequate treatment and treatment support, TB treatment should be provided by clinicians with ample experience in treating and supporting EPTB patients.

Countries reported large differences in the percentage of confirmed EPTB cases, from $10 \%$ in Romania to $80 \%$ in Sweden. Confirmation of EPTB was frequently mentioned as a challenge. Confirmation of EPTB is challenging for a number of reasons: the difficulty to obtain an adequate sample; the apportioning of the sample for various diagnostic tests resulting in non-uniform distribution of microorganisms; the pauci-bacillary nature of the specimens; the presence of inhibitors that undermine the performance of nucleic acid amplification-based techniques; and the lack of an efficient sample processing technique universally applicable on all types of extrapulmonary samples [22]. Diagnoses of EPTB without microbiological confirmation may result in over-diagnosis.

\section{Conclusion}

Diagnosis of EPTB poses challenges due to the diversity of symptoms with which EPTB may present, the low level of suspicion among clinicians, and the difficulty in obtaining an adequate sample for confirmation. Raising awareness among non-pulmonary physicians about EPTB and guidelines for diagnosis and treatment of EPTB may result in more timely and adequate diagnosis.
References

1. World Health Organization (WHO). Global tuberculosis control: WHO report 2012. Geneva: WHO; 2012.

2. Peto HM, Pratt RH, Harrington TA, LoBue PA, Armstrong LR. Epidemiology of extrapulmonary tuberculosis in the United States, 1993-2006. Clin Infect Dis. 2009;49(9):1350-7. http:// dx.doi.org/10.1086/605559. PMid:19793000.

3. Marais S, Thwaites G, Schoeman JF, Török ME, Misra UK, Prasad K, et al. Tuberculous meningitis: a uniform case definition for use in clinical research. Lancet Infect Dis. 2010;10(11):803-12. http://dx.doi.org/10.1016/ S1473-3099(10)70138-9.

4. te Beek LA, van der Werf MJ, Richter C, Borgdorff MW. Extrapulmonary tuberculosis by nationality, The Netherlands, 1993-2001. Emerg Infect Dis. 2006;12(9):1375-82. http://dx.doi. org/10.3201/eid1209.050553. PMid:17073086 PMCid:3294726.

5. Yang Z, Kong Y, Wilson F, Foxman B, Fowler AH, Marrs CF, et al. Identification of risk factors for extrapulmonary tuberculosis. Clin Infect Dis. 2004;38(2):199-205. http://dx.doi. org/10.1086/380644. PMid:14699451.

6. Fiske CT, Griffin MR, Erin H, Warkentin J, Lisa K, Arbogast PG, et al. Black race, sex, and extrapulmonary tuberculosis risk: an observational study. BMC Infect Dis. 2010;10:16. http://dx.doi. org/10.1186/1471-2334-10-16. PMid:20096113 PMCid:2823615.

7. Gonzalez OY, Teeter LD, Thanh BT, Musser JM, Graviss EA. Extrathoracic tuberculosis lymphadenitis in adult HIV seronegative patients: A population-based analysis in Houston, Texas, USA. Int J Tuberc Lung Dis. 2003;7(10):987-93. PMid:14552570

8. Al-Otaibi A, Almuneef M, Hameed T. An unusual combination of extrapulmonary manifestations of tuberculosis in a child. J Infect Public Health. 2012;5(2):203-6. http://dx.doi. org/10.1016/j.jiph.2011.11.005. PMid:22541270.

9. Markowski J, Witkowska M, Gierek T, Pasternak K, CiupińskaKajor M, Kajor M, et al. [Head and neck tuberculosis - still current problem in ENT practice]. Otolaryngol Pol. 2011;65(4):272-5. Polish. http://dx.doi.org/10.1016/ So030-6657(11)70689-8.

10. Farah MG, Rygh JH, Steen TW, Selmer R, Heldal E, Bjune G. Patient and health care system delays in the start of tuberculosis treatment in Norway. BMC Infect Dis. 2006; 6:33. http://dx.doi.org/10.1186/1471-2334-6-33. PMid:16504113 PMCid:1435913.

11. Storla DG, Yimer S, Bjune GA. A systematic review of delay in the diagnosis and treatment of tuberculosis. BMC Public Health. 2008;8:15. http://dx.doi.org/10.1186/1471-2458-8-15. PMid:18194573 PMCid:2265684.

12. Gele AA, Bjune G, Abebe F. Pastoralism and delay in diagnosis of TB in Ethiopia. BMC Public Health. 2009;9:5. http://dx.doi.org/10.1186/1471-2458-9-5. PMid:19128498 PMCid:2628652.

13. Sandgren A, Hollo V, van der Werf MJ. Extrapulmonary tuberculosis in the European Union and European Economic Area, 2002 to 2011 . Euro Surveill. 2013;18(12):pii=20431. Available from: http://www.eurosurveillance.org/ViewArticle. aspx?Articleld $=20431$

14. European Centre for Disease Prevention and Control (ECDC)/ World Health Organization Regional Office for Europe. Tuberculosis surveillance and monitoring in Europe 2013. Stockholm: ECDC; Mar 2013. Available from: http://www. ecdc.europa.eu/en/publications/Publications/Tuberculosissurveillance-monitoring-2013.pdf

15. Pace-Asciak A, Mamo J, Calleja N. The impact of immigration on tuberculosis trends in Malta 1995-2010. Eur J Public Health. 2012;22(suppl 2):10.

16. Collantes S, Soler A, Klorek N, Waslinski K; HUMA Network. Access to healthcare and living conditions of asylum seekers and undocumented migrants in Cyprus, Malta, Poland and Romania. Paris: Medecins du Monde; 2011. [Accessed Jun 2012]. Available from: http://ec.europa.eu/ewsi/UDRW/ images/items/docl_20498_605665099.pdf

17. Jakubowiak W, Korzeniewska-Koseła M, Kuś |, MichałowskaMitczuk D, Wesołowski S, Ziegman M, et al. Podręcznik gruźlicy - zalecenia NPZG. Warszawa: Instytut Gruźlicy i Chorób Płuc; 2001. Polish.

18. Kruijshaar ME, and Abubakar I. Increase in extrapulmonary tuberculosis in England and Wales 1999-2006. Thorax. 2009;64(12):1090-5. http://dx.doi.org/10.1136/thx.2009.118133. PMid:19850965.

19. Abubakar I, Griffiths C, Ormerod P; Guideline Development Group. Diagnosis of active and latent tuberculosis: summary of updated NICE guidance. BM);2012;345:e6828. http://dx.doi. org/10.1136/bmj.e6828. PMid:23077351.

20. National Institute for Health and Clinical Excellence (NICE). Tuberculosis: clinical diagnosis and management of 
tuberculosis, and measures for its prevention and control. (Clinical guideline 117). London: NICE; Mar 2011. Available from: http://www.nice.org.uk/nicemedia/live/13422/53642/53642. pdf

21. Commissie voor Praktische Tuberculosebestrijding.

Handboek TBC-bestrijding Nederland [Manual for TB control, Netherlands]. The Hague: KNCV Tuberculosis Foundation; Jul 2008. Dutch.

22. Chakravorty S, Tyagi JS. Novel multipurpose methodology for detection of mycobacteria in pulmonary and extrapulmonary specimens by smear microscopy, culture, and PCR. J Clin Microbiol. 2005;43:2697-702. http://dx.doi.org/10.1128/ JCM.43.6.2697-2702.2005. PMid:15956385 PMCid:1151876.

23. P Zatloukal,S Kos. TBC dospělých. Standard léčebného plánu. [TB of adults. Therapy standards]; 2011. Czech. PMCid:3218013.

24. K Křepela, V Kolek, P Pohunek, M Vašáková. Standard léčebného plánu - tuberkulóza dětí a mladistvých. [Therapy standard for the TB of children and adolescents]; 2012. Czech.

25. Schaberg T, Bauer T, Castell S, Dalhoff K, Detjen A, Diel R, et al. Empfehlungen zur Therapie, Chemoprävention und Chemoprophylaxe der Tuberkulose im Erwachsenen- und Kindesalter. [Recommendations for therapy, chemoprevention and chemoprophylaxis of tuberculosis in adults and children. German Central Committee against Tuberculosis (DZK), German Respiratory Society (DGP)]. Pneumologie. 2012;66(3):13371. German. http://dx.doi.org/10.1055/s-0031-1291619. PMid:22328186.

26. Prevention, Control and Management of Tuberculosis - A National Strategy for Malta. Malta; March 2012. Available from: https://ehealth.gov.mt/download.aspx?id=7031

27. NVMM-richtlijn Mycobacteriële laboratoriumdiagnostiek. Leeuwarden: Vanuit de Nederlandse Vereniging voor Medische Microbiologie (NVMM); 1 Nov 2006. Dutch. Available from: http://www.nvmm.nl/system/files/og0717-NVMM\%20 RICHTLIJN-TUBERCULOSE-NOV-06.pdf

28. Rozborilova E, Solovic I. Odborné usmernenie Ministerstva zdravotníctva Slovenskej republiky o štandardizácii diagnostiky, dispenzarizácie a liečby tuberkulózy a ostatných mykobakterióz [Professional guidance of the Ministry of Health for the management of tuberculosis and other mycobacteriosis]. Vysne Hagy: Ministry of Health and National Institute for TB, Lung Diseases and Thoracic Surgery; Jan 2006. Slovak.

29. National Tuberculosis Programme Slovenia - Clinical diagnosis and treatment of TB, 1996, update 2011.

30. Tuberkulos - Vägledning för sjukvårdspersonal. [Tuberculosis - Guidelines for healthcare professionals]. Stockholm: Socialstyrelsen; Sep 2009. Swedish. Available from: http://www.socialstyrelsen.se/Lists/Artikelkatalog/ Attachments/17744/2009-9-19.pdf 